\title{
Computational Model for Allocating the Road Pavement Funds between Implementing Units: Case Study in Tanzania
}

\author{
Vitalis Agati Ndume \\ Dar Es Salaam Institute of Technology \\ P.O.Box 2958 \\ Dar es Salaam
}

\author{
Ephata Mlavi \\ Tanzania Roads Agency \\ P.O. Box 11364 \\ Dar es Salaam
}

\begin{abstract}
This article reports on a particular module of Road Maintenance Management System was developed with the purpose of distributing Roads Maintenance Fund for the road network between the implementing units. This computational model was developed by optimizing three major parameters: priority ranking model, road network length model and budget needs model.
\end{abstract}

It is concluded that the multi stage Model combining road network length, priority ranking as well as maintenance needs provides a rational approach for allocation of maintenance fund to implementing agencies.

\section{General Terms}

Road Maintenance Model

\section{Keywords}

Road Management System, Budget split, Asset Management, Homogeneous Sections, constrained budget, unconstrained budget, Road Fund Allocation.

\section{INTRODUCTION}

An effective highway maintenance depends on several activities including the understanding of the current and the prediction of future pavement condition and deciding how to best allocate limited resource for maintenance operation[1]. In order to best allocate limited fund, the road administrators are faced with a challenge of ensuring that the little available tax payers' money is effectively utilized to maintain the roads in order to serve the society and ensure that economic growth and well-being of the society are realized. Many mathematical optimization models, supported by suitable data, can assist decision making on allocating funds into different work types. The maintenance optimization problem is, in essence, to find the optimum balance between the costs and benefits of maintenance, while taking into account various constrain [2]. It is argued in [3] even though system cannot make decision but pavement management system should assist agencies in the decision making process about which sections of pavement should be preserved, maintained and rehabilitated under budget constraints.

For a given road segment, choices have to be made between alternative treatment types and the duration to implement those treatments in order to avoid expenses in the worse case[4]. Where maintenance funds are limited, there is an additional problem of balancing the competing needs of the different segments. Maintenance tends to be underfunded relative to investment because of the smaller, less obvious nature of maintenance works relative to new infrastructure[5, 6].
In order to manage the road network in an effective and efficient way, and to have a fair distribution of the fund among implementing units in the region, the Tanzania Road Agency [7] funded the development of Road Maintenance Management System (RMMS) which is a software package capable of keeping reliable road network information in the form of highway ordinance, inventory, nodes, condition, traffic, culverts, etc, and uses these data to assist in various decision making.

The RMMS is locally developed with road engineers and software engineers in collaboration with international experts in highway and software engineers. The application interface was also programmed using the layered architecture principle. The key leading question answered in this paper is: should the fund distribution allocation between main maintenance categories depend entirely on multi-criteria priority ranking? We argued that the priority ranking score is only efficient in deciding on the priority of the road section to be treated within particular units and also assist in determining treatment type that could be selected in a homogeneous section.

The RMMS has been developed through a learning curve for more than ten years. Despite the module that estimates periodic maintenance and routine recurrent (which is beyond this paper), the budget split model is an important module to effectively distribute the available fund rationally. In addition, the system is currently being implemented in all regions in Tanzania including Zanzibar. The core function of budget split is to assist in splitting maintenance funds between implementing regions. Other uses of RMMS include contracts monitoring (including preparation of payment certificates and reporting). To make it more efficient, the RMMS has been integrated with the Geographical Information System (GIS) for mapping and has also been integrated with Highway Development and Management tool (HDM-4) for multi-year programmer and strategy analyses.

\subsection{The Concept of Asset Management}

The concept of asset management was described in [8] Asset management is an emerging effort to integrate finance, planning engineering, personnel and information management to assist agencies in managing assets cost effectively $[8,9]$ In its broadest sense, asset management is defined as "a systematic process of maintaining, upgrading, and operating assets, combining engineering principles with sound business practice and economic rationale, and providing tools to facilitate a more organized and flexible approach for making the decisions necessary to achieve the public's expectations"[10]. The main objective of asset management is to improve decision-making processes for allocating funds among an agency's assets so that the best 
return on investment is obtained. To achieve this objective, asset management embraces all of the processes, tools, and data required to manage assets effectively[11]. In regard to this, asset management is also defined as "a process of resource allocation and utilization" $[8,12]$

\subsection{Framework for Fund Allocation to Asset Management}

In practice, pavement project selection has often been based within asset "silos", that is, projects are chosen within individual management systems given a predetermined budget allocation that is not typically aligned with the performance goals of the transportation agency or with not much economic and social welfare of the road users. Instead, the allocation of resources across asset networks is often determined based on historical proportions or by legislated formula and is subject to changes due to political pressures[13]. On the other hand, globalization trends have also influence on the decision on how best to invest the fund to meet the challenges of competitor in the infrastructure[14] Consequently, agencies are at risk for pursuing and implementing less than optimal programs that waste valuable resources and are less defensible to the public and stakeholders[13, 14] . Increasingly, funding limitations pose a biggest challenge to transportation agencies; generated revenues are usually insufficient to meet the needs of the system, and prohibitive funding eligibility requirements impede their ability to flexibly and optimally allocate resources[15]. With increased flexibility, discretionary funds could be used to support pooling projects not covered by specific federal programs.

Some research literature proposes a framework for constrained fund allocation as shown in Fig. 1. The methodology in the framework is data-driven and transparent decision processes in addition to the quantification of tradeoffs and risk resulting from various allocation scenarios. A generalized five-step framework is proposed for application within management systems as well as across asset classes. A detailed review of each step in the proposed baseline framework is beyond this paper.

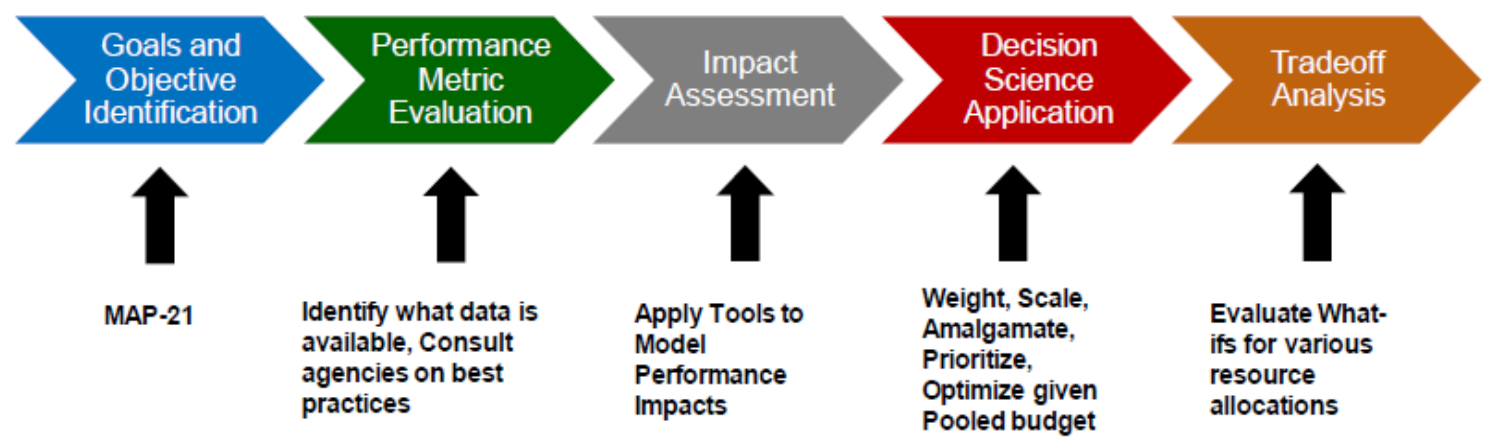

Fig 1: NCHRP -Project 08-91 Baseline Framework for fund allocation to road network Source [13]

Despite optimization in each of the chosen framework, planning and programming for maintenance for road asset network are complex processes. Many reasons are associated in the process that is, agency manages several types of physical infrastructure facilities and they are caught under political umbrella and administrative pressure as well as international treaties and agreements[13, 14].

\subsection{The Importance of Road Network}

Road network transport is an inescapable requirement to human civilization and human health where it provides considerable economic and social benefit to the society [1619]. It opens up the nerves of individuals and the nation for development. It allows pursuance of specialization in production, opening opportunities of industries to exploit economies of scale, density and scope. At the individual level, it provides general mobility where it opens access to diverse employment opportunities enabling a wide range of recreation and social activities to be reached and enjoyed. In this paper, we argue that the healthy road to road users is one which provides efficient, effective, adequate and convenient mobility and accessibility to all road users, in a safe and environmentally acceptable condition. This can only be achieved in a fair and objective budget distribution across implementing units.

The road network transport infrastructure makes a significant contribution to the GDP. It was observed in $[16-18,20]$ that in sub-Saharan region, the road network contributes up to $5 \%$ of the GDP. In recognition of the need to improve the economy, prosperity of the productive sectors and social service, among others, transport networks need maintenance and improved provision of physical road infrastructure. A good road network not only contributes to the economy but also to social wellbeing and public health. The implication of bad roads spread to the increase of $\mathrm{CO}_{2}$ due to traffic congestion. It is argued in[20] that challenges in budget allocation in road network maintenance infrastructure is lack of a proper algorithm for determining an optimum maintenance need and treatment type as well as prioritization of the needs in a given limited budget for each classification of roads. It is further noted that road condition decision for Poor, Fair and Good depends of the road type. That means what is classified as good or poor in Trunk and Regional roads may not be the same in Feeder and Rural roads.

\subsection{Transportation Asset Management State of Practice}

Currently, most transportation agencies use traditional techniques such as ranking and prioritization to allocate resources for maintaining, upgrading and operating their physical assets[21].

Most agencies use "worst first" approach, which means allowing their assets to deteriorate to a

level that results in spending millions of dollars on reconstruction[15]. Another model for planning and scheduling of asset in an uncertain environment in which the process industry are imbedded is stochastic optimization. It is 
argued in[3] that pavement maintenance is one of the major hectic scheduling to public agencies. Insufficient investment or inefficient maintenance strategies lead to higher expenses in the long term. Similarly, under budgetary restrictions, the optimal allocation of resources becomes a crucial aspect.

Even though Strategic Long-Term Investment Planning (SLTIP) requires trade-off of investment strategies across a variety of asset types, the common practices in many agencies is to use traditional techniques to allocate resource for maintaining the road network of transportation assets. The pitfall of budget cut off prioritization has been noted in some literature[1, 12, 13, 22-28]. However, priority ranking is still found near-optimal in utilization of available resources specifically scarce funding. The author argues that to make it more rational, the available fund should be optimized for economic benefit of the road users and should encompass network length and as well as the need of respective implementing unit without excluding priority score.

The need for a robust optimization tool to support long-term planning in civil infrastructure asset management is motivated by the sensitivity of timing on the effectiveness of an "action" or "choice" in the process of operating civil assets[13]. If there is no action taken in Very Good road section, it may deteriorate to Good and later to Fair and finally to Poor. Such tradeoff causes exponential increases in investment of road maintenance. Fig. 2 below shows the prediction of investment if no action is taken in a Very Good road section as time increases.

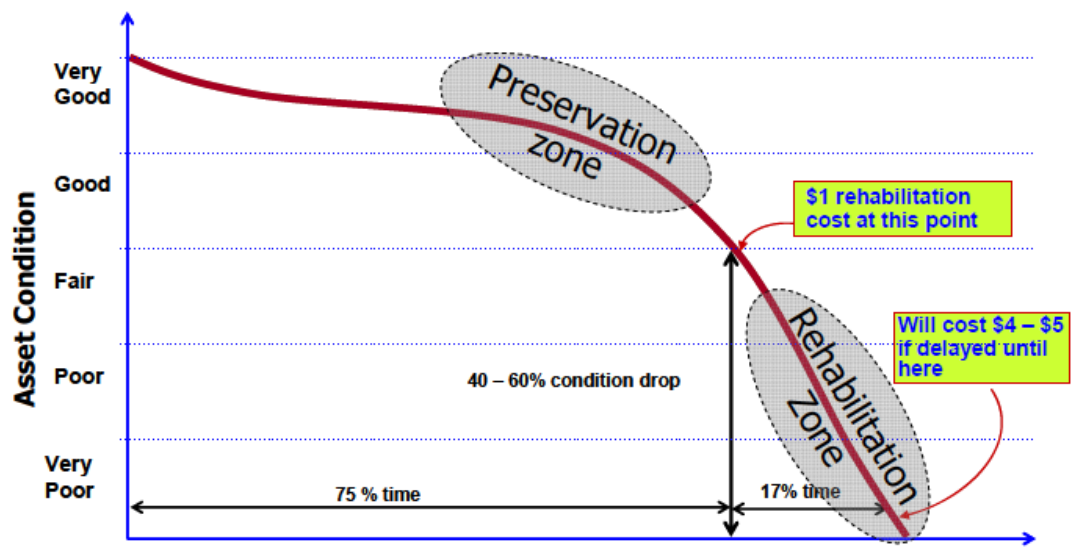

Age (years)

Fig. 2: Typical Asset deterioration and time sensitivity of treatment Source: [13]

\section{MATERIAL AND METHODS IN DEVELOPING BUDGET SPLIT}

The main methodology in developing the RMMS system is deployment of V-Model model in system development. The RMMS engineers and international transportation experts scientifically study the requirement of the TANROADS objective in road planning and evaluate different ways of distributing the fund to the region that would enable each region to get at least some fund based on road network length, unconstrained and constrained needs as well as multi-criteria priority ranking for Routine recurrent and periodic maintenances. These three parameters become the input for the budget split. After approving the specification, a stakeholder workshop was conducted to improve the analysis. The next step was to design and code the system. The algorithm was designed and implemented in RMMS. The report format and user interface ware prototyped by collaboration between RMMS engineers and software programmer. White box testing was conducted in the developing environments where five experts in road planning were commissioned to test the system.

After White Box testing, the client organizes a compressive test outside the development environment. The comprehensive test is normally organized by selecting RMMS regional engineers and other collaborators. During testing, black boxes test was deployed where each tester group was assigned responsibility. In this workshop, comments to improving the algorithm were collected and improvement was made thereafter. The system is therefore being implemented in 25 regions in the country.

\section{RESULT AND DISCUSSION 3.1.Homogeneous Sections}

Homogeneous sectioning of a road network is the process of combining adjacent sub-links together to form sections. Each sub-link in a section has parameters that match the other sublinks in the section according to a set of criteria. These criteria are based on traffic flow, pavement condition and inventory characteristics and optionally on treatment type/accessibility. Sectioning by condition occurs before sectioning by treatment type. All of the sub-links in a section must have identical values for the following pre-defined parameters regardless of sectioning method: Traffic of the link, ESAL values, link number or downstream, pavement type (e.g., surface treated, asphaltic material, gravel, earth), number of lanes, carriageway type (Single/Dual) and user given threshold, etc. In this process the algorithm Sections joined the section of the adjacent link links, provided the sub-links are adjacent and have similar characteristics motioned in table1. Sections are generated by changes in key factors from one sub-link to the next. If the key factor changes more than the user given threshold value the sectioning routine generates a maintenance section. The Information on Table 1 represents key factors that can be used by the algorithm during sectioning. 
Table 1: Key Factors used for Homogeneous Sectioning algorithm

\begin{tabular}{|l|l|}
\hline Paved Roads & Unpaved Roads \\
\hline Roughness (percentage) & Traffic (percentage) \\
Traffic (percentage) & Overall condition (indices) \\
Cracking range (indices) & Carriageway shape (indices) \\
Pavement age (y/n) & Surface condition (indices) \\
Structural number $(\mathrm{y} / \mathrm{n})$ & Differentiate EG and EE (y/n) \\
Carriageway width $(\mathrm{y} / \mathrm{n})$ & Pavement age $(\mathrm{y} / \mathrm{n})$ \\
Traffic flow $(\mathrm{y} / \mathrm{n})$ & Carriageway width $(\mathrm{y} / \mathrm{n})$ \\
& Traffic flow $(\mathrm{y} / \mathrm{n})$ \\
\hline
\end{tabular}

For each homogenous section, an appropriate (if any) periodic maintenance intervention is assigned in the treatment matrix. The treatment matrix only includes economically feasible works, though some engineering judgement can be applied to derive a more balanced matrix. With the homogenous section algorithm, the needs for spot improvements are based on the needs registered as part of the technical engineering condition surveys. Each work is assigned a unit cost, which when multiplied by the section length or area derives the estimated costs for the proposed work. The computation cost of the homogenous section of the PM is as in equestion1 bellow:

$$
P_{\mathrm{CLink}}=\sum_{1}^{n}(Z A F)(U C)(S L E N G T H)(A S W) \text {----(1) }
$$

where:

$P C_{\text {Link }}$ is the Periodic maintenance costs of the section

$\mathrm{ZAF}$ is the Zonal Adjustment Factor

$U C$ is the Unit Costs $/ \mathrm{m}^{2}$

SLENGTH is the Section Length $(m)$

$A S W \quad$ is the weighted Average Section Width (m)

Likewise, the RRM is based on the quantity of each work type such as Crack Filling, Local Sealing, Cut Out and Patch, Pothole Patching, Surface Repair, Light Grading, Heavy Grading, Crack Filling-Sealed Shoulders, Local SealingSealed Shoulders, etc. The equation 2 below is a model for Routine recurrent.

$$
R_{C \text { Link }}=\sum_{1}^{n} Q_{\text {Sub-link }} \times U C_{w t}
$$

where:

$$
\begin{array}{ll}
R R M C_{\text {Link }} & \text { is the maintenance costs of section } \\
Q & \text { is the Quantity of each work type } \\
U C & \text { is the Unit Costs } / \mathrm{m}^{2} \\
w t & \text { Work Type }
\end{array}
$$

The need $\mathrm{N}$ is a function of two models PM and RMM calculated in equation 3 as follows.

$N_{B}=\sum_{l=1}^{n} P_{C L i n k}+\sum_{l=1}^{n} R_{C \text { Link }}$

\subsection{Budget Split Module}

The objectives of the Budget Split Module are to:

i. Accumulate the maintenance needs across all regions and maintenance type ii. Analyse the consequences of budget allocations in terms of distribution between the regions and maintenance types

The model uses the output of the analyses of the Routine/Recurrent Maintenance priority index and the Periodic Maintenance/MCA score values carried out on the network. To analyse the consequences of budget constraints, each module is analysed separately. The Budget Split Model can then be applied to the unconstrained analyses to review the consequences in terms of distribution between the regions and maintenance type under different budget levels.

The model accumulates the needs (unconstrained) of the estimated routine, recurrent and periodic maintenance and spot improvement across all regions included in the analysis. A budget split model is based on analysis of unconstrained results of the road network. The model then prioritises the needs under the given budget constraint, using the following parameters as an input:

i. Distribution of budgets, where all viable projects compete for the same budget using MCA score

ii. Distribution of budgets by road lengths where a region with higher network is given score factors

iii. Distribution of budget using each region's share of the total unconstrained needs

When prioritising the needs under the user given budget constraints $T_{B}$ the algorithm for Budget Split Model will use the same prioritisation models as adopted in the Routine/Recurrent Maintenance Model and the Periodic Maintenance Model. When distributing budgets according to road length, each region will get a budget which corresponds to its share of the total road length.

$$
\left.L_{B}=\left(L_{R} / L_{T}\right) \times T_{B}\right) \times F_{l}
$$

Where

$L_{B} \quad$ is the budget based on road length of Region A

$L_{R} \quad$ is the length of roads in Region A

$L_{T} \quad$ is the total length of roads in all regions

$T_{B} \quad$ is the total budget available

$F_{l} \quad$ is the factor giving the share of the total budget to be distributed using

this model (road length) 
When distributing budgets according to total unconstrained needs, each region will get a budget which corresponds to its share of the total maintenance needs computer in equation 5 .

$\left.U_{B}=\left(U_{n r} / U_{t n}\right) \times T_{B}\right) \times F_{3}$

Where

$U_{N}$ is the budget based on unconstrained maintenance needs of Region A

$U_{n r} \quad$ is the unconstrained maintenance needs of Region A

$U_{t n} \quad$ is the total maintenance needs of all regions

$T_{B} \quad$ is the total budget available

$F_{3} \quad$ is the factor giving the share of the total budget to be distributed using

The default values for the weights between the models are $50 \%\left(F_{1}\right), 25 \%\left(F_{2}\right)$ and $25 \%\left(F_{3}\right)$ respectively. $F_{i}$ is used to allocate the percentage of the budget which will be distributed..This allows all projects to compete equally across regional boundaries for the budget. Finally, after setting the parameters, the BSM will output the combined distribution budget of each region calculated as follows:

$B_{R i}=N_{B}+L_{B}+U_{B}$

\subsection{Output of the Budget Split Module}

The module provides the following output:

- Budget allocations for each region and maintenance type

- Percentage distribution between regions and maintenance type

\section{CONCLUSION AND RECOMMENDATION}

\subsection{Conclusion}

The combination of road network length, multi criteria analysis and the amount of fund required by implementing unit appears to implement the concept of "KEEP GOOD CONDITION GOOD" which is a the basis for road asset management. It underlies a base for a fair competition in the scarce fund between the regions. The developed algorithm for multiple stage approach in budget split into region overcomes the limitation of the distributing the budget based only on prioritizing index instead it proved an optimal allocation of limited resource available. This approach can help transportation agencies to deal with the challenges of providing the best possible conditions of the road network system under the ever increasing stringent constrains in financial and other resources.

It should be noted that budget limitation is not the only constraints imposed in road maintenance optimization models, additional constraints may be necessary to prevent corner solution or the model extrapolating relationship beyond the range over which they apply.

It is concluded that any road maintenance management system will succeed if there is a local capacity for maintaining, managing the system development and debugging. It is also important that the stakeholders are involved during the development process and during modeling of the module.
Furthermore, optimization of pavement structure should be optimized to allow trade-off analysis that accommodates long term projection and forecasting of deterioration.

\subsection{Recommendations}

For one year estimation of the budget, this approach excels better; however, if analysis needs allocation of fund in more than a year then other optimization models such as HDM4 or RONET may provide realistic estimation of budget allocation for five or twenty years. There calibration RMMS to meet HDM4 need remain agape for study.

Research in Road fund budget allocation is continues process. Therefore it is recommended that more work is requires to investigate robust way of optimizing the limited resource in the cause of Road user benefit.

\section{REFERENCES}

[1] S. Fallah Fini, et al., "Optimizing highway maintenance operations: dynamic considerations," System Dynamics Review, vol. 26, pp. 216-238, 2010.

[2] R. Dekker, "Applications of maintenance optimization models: a review and analysis," Reliability Engineering \& System Safety, vol. 51, pp. 229-240, 1996.

[3] C. Torres-Machí, et al., "An iterative approach for the optimization of pavement maintenance management at the network level," The Scientific World Journal, vol. 2014,2014

[4] D. Vannier, "Why Industry Needs Asset management tools," Journal of Computing in Cvil Engineering, vol. 15, January 20012001.

[5] J. Semmens, "De-socializing the roads," Street Smart: Competition, Entrepreneurship, and the Future of Roads, pp. 25-41, 2006.

[6] G. J. Zietlow, High Way Capacity manual: Role of Private Sector in Managing and Maintaining Roads vol. Transaction New Brunswick, 2006.

[7] TANROADS, "Tanzania Road Maintenance management Ssystem,Development of Roads Mentor: RMSS 5 Ssystem Process," TANROADS2010.

[8] S. McNeil, et al., "Asset management: What is the fuss?," Transportation Research Record: Journal of the Transportation Research Board, pp. 21-25, 2000.

[9] P. E. Krugler, et al., "Asset management literature review and potential applications of simulation, optimization and decision analysis techniques for rightof-way and transportation planning and programming," Texas Transportation Institute The Texas A\&M University System College Station, 2007.

[10] OECD, "Asset management fo the Road sector:Economics and Administration, Maintenance, Traffic and Transport Planning.," in 2 vol. ITRD NUMBER: E108508, ed. Paris -France: OECD Publications, 2, rue André-Pascal, 75775 Paris Cedex 16, France., 2001.

[11] C. Nemmers, "Transportation asset management," Public Roads, vol. 61, 1997.

[12] S. R. Cooksey, et al., "Asset management assessment model for state departments of transportation," Journal of Management in Engineering, vol. 27, pp. 159-169, 2010. 
[13] K. M. Ford, et al., "Methodology and Benefits of a Performance-Based, Cross-Asset Resource Allocation Approach Towards Systemic Transportation Infrastructure Management," in Transportation Research Board 93rd Annual Meeting, 2014.

[14] V. A. Varma, et al., "Enterprise-wide modeling \& optimization-An overview of emerging research challenges and opportunities," Computers \& Chemical Engineering, vol. 31, pp. 692-711, 2007.

[15] S. G. Kachua, "A Large-Scale Optimization Algorithm to Support Cross-Assets Long-Term Planning in Transportation Asset Management," University of New Brunswick, Department of Civil Engineering, 2012.

[16] M. E. Abdon G.M. Maregesi, "Assessment of Tanroads Road Maintenance Management System," Msc. Engineering, University of Dar es Salaam, Dar e salaam, 2012.

[17] F. Abeid. (2006, Feb 5,2006) Can the transport sector development program deliver MKUKUTA. Construction Business national Construction Council.

[18] E. C. M. Ally S. Nyamawe, "Road Safety: Adoption of ICT for Tracking Vehicles Over-speeding in Tanzania," International Journal of Computer Applications vol. 96, June 20142014.

[19] CIDA. (2005, Canadian international Development agency. ICT as a tool for poverty Reduction. Health in north Africa and Middle east.

[20] V. Ndume, Lwiza J. Mchumvu Y , Masika R Ndyamukama V., "ICT As tool for Delivering Mkukuta: The Case of Road Maintainance Managemant System International " in Role of Engineering in Poverty Reducation., ed, 2006.

[21] M. E. Ozbek, "Development of a comprehensive framework for the efficiency measurement of road maintenance strategies using data envelopment analysis," Virginia Tech, 2007.
[22] C. A. R. E.Cooperation, "SECTOR ASSESSMENT (SUMMARY): TRANSPORT, AND SUMMARY: TRANSPORT, AND INFORMATION AND COMMUNICATION TECHNOLOGY," Central Asia Regional Economic Cooperation2014.

[23] L. Š. Gediminas DAVULIS, "MODELLING AND OPTIMIZATION OF TRANSPORTATION COSTS," vol. 1 pp. $18-29,2010$.

[24] J. S. Gillespie, "ESTIMATING USER COSTS AS A BASIS FOR INCENTIVE / DISINCENTIVE AMOUNTS IN HIGHWAY CONSTRUCTION CONTRACTS," Virginia Transportation Research Council (A Cooperative Organization Sponsored by the Virginia Department of Transportation and the University of Virginia) In Cooperation with the U.S. Department of Transportation Federal Highway Administration February, 19981998.

[25] S. Guenther. (2014, June 14, 2012). Application of Cross-Asset Optimization in Transportation Asset Management: A Survey of State Practice and Related Research. Preliminary Investigation : Caltrans Division of Research and Innovation.

[26] Gyeke, "ROAD INFRASTRUCTURE MANAGEMENT STRATEGIC FRAMEWORK FOR AFRICA: A CASE STUDY OF NIGERIAN ROADS," School of Engineering Technology, 2010.

[27] G. D. Mrema, "Traffic Congestion in Tanzania major Cities Causes, Impacts and Suggested Mitigation to the problem," in Challenges In Addresssing Traffic Congestion and Enhencing Road safety for National Development Naura Springs Hotel, 2011, pp. pg 1-19.

[28] A. A. A. Silas O. A, Isichei C, Echejoh G. O, Manasseh M. N and Olu-Silas R. A., "Road traffic accident deaths as seen in a Tertiary Health Centre Jos University Teaching Hospital (JUTH)," presented at the Tertiary Health Centre Jos University Teaching Hospital, Nigeria, 2011 